Article

\title{
Impact of Large-Scale Wind Power Integration on Small Signal Stability Based on Stability Region Boundary
}

\author{
Wenying Liu, Rundong Ge *, Huiyong Li and Jiangbei Ge
}

State Key Laboratory of Alternate Electrical Power System with Renewable Energy Sources, Mailbox 435, North China Electric Power University, No. 2 Beinong Road, Changping district, Beijing 102206, China; E-Mails: liuwenyingls@ncepu.edu.cn (W.L.); lihuiyong311@126.com (H.L.); gejiangbei1205@163.com (J.G.)

* Author to whom correspondence should be addressed; E-Mail: gerundong@ncepu.edu.cn; Tel./Fax: +86-10-6177-3725.

External Editor: Arnulf Jäger-Waldau

Received: 15 September 2014; in revised form: 21 October 2014 / Accepted: 3 November 2014 / Published: 10 November 2014

\begin{abstract}
Up until now, study results on the impact of large-scale wind power integration on small signal stability have often been in conflict. Sometimes, the conclusions are even completely opposite, making people unable to agree on which is right. The reason behind this phenomenon is that most of these studies are based on a certain grid and typical working conditions, so conclusions are reached by comparing changes in oscillation mode, one by one. This study method lacks a broader perspective, and often reflects only a part of the grid conditions. However, the small signal stability region boundary describes the critical operating range of power system small signal stability as a whole, making possible an overall evaluation of the system from a more macro perspective. Thus it is more suitable for analysis of the impact of large-scale wind power integration on small signal stability. Based on the above, using the model of wind farm integration to the single-machine infinite bus power system, this paper studies the impact of wind power integration scale and the coupling strength with synchronous generator on small signal stability through the comparison of the stability region boundaries, thus providing a new method and support for analyzing the impact of wind power integration on small signal stability.
\end{abstract}

Keywords: large-scale wind power; small signal stability; small signal stability region boundary 


\section{Introduction}

With the aggravation of the energy crisis and increasingly prominent environmental problems, renewable energy has become the most effective solution [1]. Among the various methods of renewable energy generation, wind power generation, seen as the most technologically sophisticated and economically beneficial [2], has been developing rapidly [3,4]. However, there are great differences in structure and control between wind turbine and conventional units [5]. Thus, great attention [6,7] has been paid to large-scale wind power integration. Specifically, the impact of large-scale wind power integration on power system small signal stability is a high research priority.

To date, many scholars have researched this subject. Shi et al. [8] adopted the Monte Carlo simulation technique to figure out the relationship between small signal stability and the wind generation intermittence. Bu et al. [9] studied the impact of stochastic uncertainty of grid-connected wind generation on probabilistic small signal stability of the power system based on the Gram-Charlier expansion and the probabilistic density function of critical eigenvalues. Soleimanpour and Mohammadi [10] presented a new method based on two-point estimation for probabilistic eigenvalues analysis in power systems containing wind energy, obtaining information on probabilistic system stability with less computation. Slootweg et al. [11] took a system with two generators and a two-area test system with four generators as their example and studied the impact of wind power integration on power system small signal stability by observing the movement of the eigenvalues, investigated by gradually replacing the power generated by the synchronous generators with wind power. It was concluded from the results that due to the reduction of the number of synchronous generators participating in the oscillation, wind power integration will improve the damping of the power system in which constant speed wind turbines have better effects than variable speed turbines. Anaya-Lara et al. [12] tested a three-generator system and came to similar conclusions. However, not all researchers agreed. Mendonca and Peas Lopes [13] tested a three-area system with six generators to study the influence of wind power integration, using the eigenvalue method and multi-scenario technology. Their results indicated that when the change of wind power output counteracts that of the conventional units in the same area, the damping of oscillation mode does not change significantly. Knuppel et al. [14] analyzed the impact of full-load converter interfaced wind turbines on small signal stability of power system with wind energy integration based on the eigenvalue method and sensitivity method. Their results also indicate that wind energy does not participate in the power system oscillation mode and the characteristics of the system oscillation mode are virtually unchanged by wind energy penetration. Meanwhile, some other studies indicated that wind power integration will reduce the power system small signal stability in certain circumstances. Gautam et al. [15] replaced the DFIG (Doubly Fed Induction Machine) machines with conventional generators and then studied the impact of wind power penetration on the power system small signal stability by evaluating the sensitivity of its eigenvalues. Their results showed that wind power exerts a positive influence on part modes but adversely affected the other modes. Hagstrom et al. [16] proposed that integration of wind power generated by DFIG and DDSG (Direct Drive Synchronous Generator) will reduce the damping of oscillation mode by time-domain simulation analysis of Nordic grid. Sanchez-Gasea et al. [17] pointed out that wind power integration had different effects on small signal stability under different operation modes. Compared with the synchronous machines, large-scale wind power integration enhances the damping of oscillation mode. However, when the scale of wind power is small, the damping of 
oscillation mode is reduced. Meanwhile, wind power taking the place of the synchronous machines will lead to the disappearance of part oscillation modes.

Generally speaking, the above studies are divided into two kinds of approaches. One is based on probability, which considers the uncertainty of wind energy and determines the probability distribution of a power system's critical eigenvalues to find the impact of wind power's stochastic uncertainty factors on power system small signal stability. Another approach is a deterministic method, which applies to a certain grid and typical working conditions; conclusions are reached by comparing changes in oscillation mode one by one with the eigenvalue method or time-domain simulation. These study results are often in conflict, making people unable to agree on which is right. The reason is that most of these research methods are based on a certain grid and typical working conditions, reflecting only part conditions of power system small signal stability but lacking a more macro perspective.

However, the small signal stability region boundary [18-20] describes the critical operating range of small signal stability of the system as a whole, making overall evaluation of the system state possible from a more macro perspective. Thus it is more suitable for analysis on the impact of large-scale wind power integration on small signal stability. At present, the small signal stability region boundary theory is mainly adopted in the field of conventional power systems and has no application in the study of the impact of wind power on small signal stability yet.

Based on this, the theory of the small signal stability region boundary was studied first. By using the model of wind farm integration to the single-machine infinite bus power system, this paper studies the impact of wind power integration scale and the coupling strength with synchronous generator on small signal stability through comparison of the stability region boundaries, searching for a new way of thinking about and analyzing the impact of wind power integration on small signal stability.

\section{The Determination Method of Small Signal Stability Region Boundary and Its Steps}

\subsection{Basic Theory}

The dynamics model [21] of power systems can be described by a set of differential-algebraic equations:

$$
\left\{\begin{array}{l}
\dot{x}=f(x, y, k) \\
0=g(x, y, k)
\end{array} .\right.
$$

In Equation (1), $x \in R^{\mathrm{m}}$ is the stated variable of the system, $y \in R^{\mathrm{n}}$ is the algebraic variable, and $k \in R^{\mathrm{p}}$ is the system parameter.

Holding the variable $k$ unchanged, Equation (2) satisfies the formula for the equilibrium point of the system.

$$
\left\{\begin{array}{l}
\left.f(x, y)\right|_{k_{0}}=0 \\
\left.g(x, y)\right|_{k_{0}}=0
\end{array}\right.
$$

Then Equation (2) can be linearized as Equation (3):

$$
\left[\begin{array}{l}
\Delta \dot{x} \\
0
\end{array}\right]=\left[\begin{array}{ll}
f_{x} & f_{y} \\
g_{x} & g_{y}
\end{array}\right]\left[\begin{array}{l}
\Delta x \\
\Delta y
\end{array}\right],
$$

in which: 


$$
\left\{\begin{array}{l}
f_{x}=\partial f /\left.\partial x\right|_{k_{0}} \\
f_{y}=\partial f /\left.\partial y\right|_{k_{0}} \\
g_{x}=\partial g /\left.\partial x\right|_{k_{0}} \\
g_{y}=\partial g /\left.\partial y\right|_{k_{0}} .
\end{array}\right.
$$

When the $g_{\mathrm{y}}$ is nonsingular, the algebraic variables can be eliminated in Equation (3) to create Equation (5).

$$
\Delta \dot{x}=J(x, y, k) \Delta x,
$$

where

$$
J(x, y, k)=f_{x}-f_{y} g_{y}^{-1} g_{x} .
$$

In Equation (6), $J$ is the characteristic matrix of the system. According to Lyapunov's first theorem, the small signal stability of the system is decided by the eigenvalues of the characteristic matrix $J$.

\subsection{Composition of Small Signal Stability Region Boundary}

Under normal circumstances, the eigenvalues are normally less than zero and the system works steadily. However, with the change of parameter K, three circumstances may appear in which the eigenvalue makes the system achieve the small signal stability region boundary: (1) A pair of real eigenvalues cross the imaginary axis, causing saddle node bifurcation (SNB); (2) A pair of conjugate complex eigenvalues cross the imaginary axis, causing Hopf bifurcation (HB); and (3) Matrix $g_{\mathrm{y}}$ is singular, causing singularity induced bifurcation (SIB). Thus the small signal stability region boundary $\left(\partial \Omega_{s s s}\right)$ consists of these three types of point set.

$$
\partial \Omega_{s s s r}=\{S N B s\} \bigcup\{H B s\} \bigcup\{S I B s\}
$$

In Equation (7), $S N B S$ is the point set of saddle node bifurcation, $H B S$ is the point set of Hopf bifurcation, and SIBS is the point set of singularity induced bifurcation. Among these, Hopf [22,23] bifurcation relates to the oscillatory instability of the power system. This paper mainly focuses on the small signal stability region boundary formed by Hopf bifurcation in the active power injection space.

\subsection{Method and Steps}

Supposing power sources 1 and 2 are two arbitrary power supplies in the power system associated with the dominant oscillation mode, the balancing machine chosen is one large unit that is unrelated to the dominant oscillation mode and far away from the oscillatory areas. Keeping the other nodal injection power constant except for the balancing machine, the injected active power $P_{1}$ of power source 1 and $P_{2}$ of source 2 will form a two-dimensional small signal stability region boundary.

The system small signal stability region boundary is determined by way of system simulation, point by point. The specific method and steps are as follows:

(1) Select one small signal stable operating point in the power system as the initial searching point.

(2) Keep the other power injections constant, change the active power output $P_{1}$, and get the system a new balance point. Then, according to the basic theory in Section 2.1, recalculate the system's eigenvalue of the dominant mode accordingly. 
(3) Determine whether the Hopf bifurcation shown in Section 2.2 occurs in the system according to the eigenvalues. If Hopf bifurcation occurs, record the parameters; if Hopf bifurcation does not occur, adjust the active power output $P_{1}$ according to the real parts of the eigenvalues until Hopf bifurcation occurs in the system.

(4) Change the active power output $P_{2}$ with a fixed step size. For each $P_{2}$, repeat steps (2) and (3) to obtain the new Hopf bifurcation point.

(5) When the power output reaches the upper or lower limits or the power flow has no solution in step (4), stop searching.

Connect the Hopf bifurcation points with a smooth curve to obtain the Hopf bifurcation point set of the power system. Considering the existence of upper and lower limits of actual power output, the upper and lower limits of actual power output and the Hopf bifurcation point set together make the power system small signal stability region boundary. The whole process is shown in Figure 1.

Figure 1. Flow chart of small signal stability boundaries calculation.

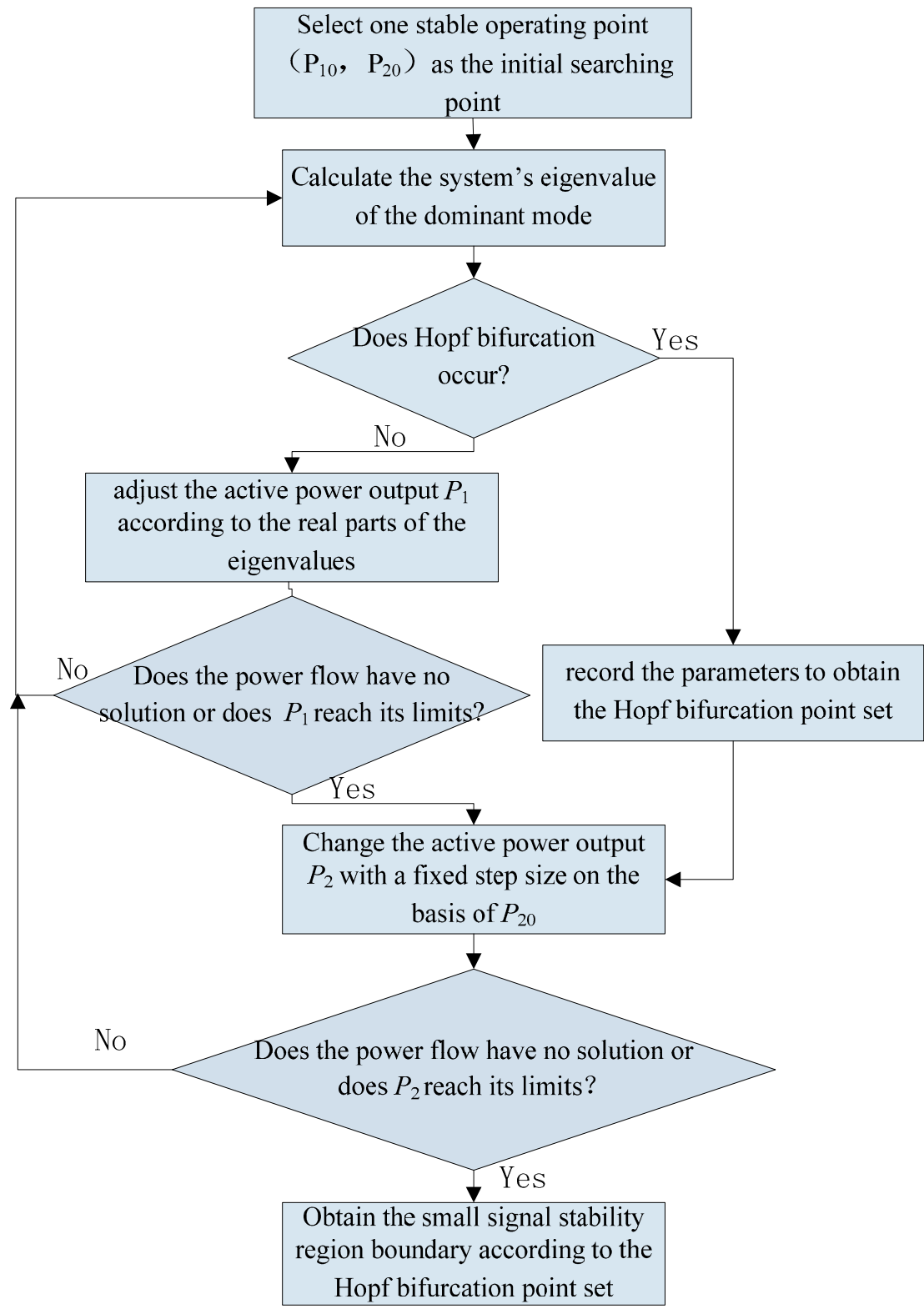




\section{The Wind Turbine and Wind Farm Models}

\subsection{Model of DFIG Wind Turbine}

This paper adopts the current mainstream wind turbine, the doubly fed induction generator (DFIG) [24-26], to study the impact of wind power integration on small signal stability. The $2 \mathrm{MW}$ wind turbine built in the software DIgSILENT/PowerFactory was used to do simulations. Its mathematical models are as follows.

\subsubsection{The Aerodynamic Model}

The aerodynamic model of wind turbines is:

$$
P_{M}=\rho C_{p}(\lambda, \beta) \pi R^{2} V_{w}^{3} / 2 .
$$

In Equation (8), $P_{M}$ is the mechanical power of the wind turbine, $\rho$ is the air density, $R$ is the rotor radius, $\lambda$ is the tip speed ratio; $\beta$ is the blade pitch angle, and $C_{p}$ is the power coefficient as a function of $\lambda, \beta . C_{p}$ changes along with $\lambda$ and $\beta$, and $V_{\mathrm{w}}$ is the wind speed.

\subsubsection{The Model of the Drive-Train System}

The drive-train system of DFIG adopts the so-called two-mass model. In this, a mass block includes the low speed shaft's flexibility to reflect the wind turbine's inertia, and another mass block reflects the generator's inertia. The model of the drive-train system is given by a system of differential equations, as follows:

$$
\left\{\begin{array}{l}
\dot{\omega}_{t}=\frac{1}{2 H_{t}}\left[T_{m}-K_{s} \theta_{s}-D\left(\omega_{t}-\omega_{r}\right)\right] \\
\dot{\omega}_{r}=\frac{1}{2 H_{g}}\left[K_{s} \theta_{s}+D\left(\omega_{t}-\omega_{r}\right)-T_{e}\right] \\
\dot{\theta}_{s}=\omega_{t}-\omega_{r}
\end{array} .\right.
$$

In Equation set (9), $\theta_{s}$ is the twist in the shaft system, $\omega_{t}$ is the speed of the wind turbine, $\omega_{r}$ is the speed of the generator rotor, $H_{t}$ is the inertia constant of the wind wheel, $H_{g}$ is the inertia constant of the generator's rotor, $T_{m}$ is the wind turbine's mechanical torque, $T_{e}$ is the generator's electromagnetic torque, and $D$ and $K_{s}$ respectively represent the drive-train system's equivalent damping coefficient and stiffness coefficient.

\subsubsection{Model of the Induction Generator}

In the reference $\mathrm{d}-\mathrm{q}$ coordinate system, the stator adopts the generator convention, while the rotor adopts motor convention. Thus the voltage equations of the doubly fed induction generator are given as follows:

$$
\left\{\begin{array}{l}
u_{d s}=\dot{\psi}_{d s}-\omega \psi_{q s}-R_{s} i_{d s} \\
u_{q s}=\dot{\psi}_{q s}+\omega \psi_{d s}-R_{s} i_{q s} \\
u_{d r}=\dot{\psi}_{d r}-\omega_{s} \psi_{q r}+R_{r} i_{d r} \\
u_{q r}=\dot{\psi}_{q r}+\omega_{s} \psi_{d r}+R_{r} i_{q r} .
\end{array}\right.
$$


In Equation set (10), all the quantities are normalized values. Here, $u, I, R$, and $\psi$ respectively represent voltage, current, resistance, and flux; the subscripts $d$ and q respectively represent the $d$ axis and $\mathrm{q}$ axis components; and the subscripts $\mathrm{r}$ and $\mathrm{s}$ respectively represent the rotor and stator. The synchronous rotational speed is represented by $\omega ; \omega_{s}=\omega-\omega_{r}=s \omega$ (the slip speed), where $\mathrm{s}$ is the slip ratio.

The flux equations are:

$$
\left\{\begin{array}{l}
\psi_{d s}=-L_{s s} i_{d s}+L_{m} i_{d r} \\
\psi_{q s}=-L_{s s} i_{q s}+L_{m} i_{q r} \\
\psi_{d r}=L_{r r} i_{d r}-L_{m} i_{d s} \\
\psi_{q r}=L_{r r} i_{q r}-L_{m} i_{q s}
\end{array},\right.
$$

in which $L_{s s}=L_{s}+L_{m}, L_{r r}=L_{r}+L_{m}, L_{s}, L_{r}, L_{m}$ are the self-inductance and mutual inductance of stator and rotor, respectively.

Arrange Equations (10) and (11) and set the stator voltage vector of DFIG as the q axis. In the d-q coordinate system, select the stator's flux $\left(\psi d s, \psi_{d s}\right)$ and the rotor's current $\left(i_{d r}, i_{q r}\right)$ as state variables. The state equations for DFIG are:

$$
\left\{\begin{array}{l}
\dot{\Psi}_{d s}=-\frac{R_{s}}{L_{s s}} \Psi_{d s}+R_{s} L^{\prime \prime} i_{d r}+\omega \Psi_{q s}+u_{d s} \\
\dot{\Psi}_{q s}=-\frac{R_{s}}{L_{s s}} \Psi_{q s}+R_{s} L^{\prime \prime} i_{q r}-\omega \psi_{d s}+u_{q s} \\
\dot{i}_{d r}=\frac{1}{L^{\prime}}\left(-R_{r} i_{d r}+u_{d r}+\omega_{s} L^{\prime} i_{q r}+\omega_{s} L^{\prime \prime} \Psi_{q s}-L^{\prime \prime} \dot{\Psi}_{d s}\right) \\
\dot{i}_{q r}=\frac{1}{L^{\prime}}\left(-R_{r} i_{q r}+u_{q r}-\omega_{s} L^{\prime} i_{d r}-\omega_{s} L^{\prime \prime} \Psi_{d s}-L^{\prime \prime} \dot{\Psi}_{q s}\right)
\end{array},\right.
$$

where

$$
L^{\prime}=L_{r r}-\frac{L_{m}^{2}}{L_{s s}}, L^{\prime \prime}=\frac{L_{m}}{L_{s s}} .
$$

\subsubsection{The Overall Control Model of DFIG}

The overall control system of a doubly fed variable speed wind turbine is shown in Figure 2.

The control system mainly consists of two sub-systems: wind turbine control and DFIG control. Wind turbine control includes a speed controller and a pitch angle controller. The pitch angle controller is mainly used to limit the active power of a wind turbine when wind speed exceeds the rated wind speed. The pitch angle is kept at $0^{\circ}$ under the normal working state. The speed controller provides a reference value of active power, $P_{\text {grid }}^{\text {ref }}$, for the rotor-side converter. DFIG control includes rotor-side converter controller and grid-side converter controller, which are mainly used to control its active and reactive power. For the reactive power control of the converter, set a fixed value for the rotor-side converter's $Q_{\text {grid }}^{\text {ref }}$, according to the requirement for the reactive power exchange degree of the interconnection node at steady operation state; set the value of rotor-side converter's $Q_{c o n v}^{\text {ef }}$ to 0 to ensure no reactive power change between the rotor and the grid at normal operation state. Through the converter control, the DFIG 
can realize the decoupling of active power and reactive power. More details of the DFIG control can be found in document [26] (Hansen et al., 2003).

\subsection{Wind Farm Model}

As the capacity of a single wind turbine is very small, the wind farm is often composed of large numbers of wind turbines. In this paper, $m$ doubly fed induction generators are equivalent to one according to the single machine equivalent method [27,28] (Fernández et al., 2008; Ali et al., 2008). The equivalent model is given in Equation (13).

$$
\left\{\begin{array}{c}
S_{e q}=\sum_{i=1}^{m} S_{i}, P_{e q}=\sum_{i=1}^{m} P_{i}, Q_{e q}=\sum_{i=1}^{m} Q_{i} \\
x_{m-e q}=\frac{x_{m}}{m}, x_{s-e q}=\frac{x_{s}}{m}, x_{r-e q}=\frac{x_{r}}{m} \\
r_{s-e q}=\frac{r_{s}}{m}, r_{r-e q}=\frac{r_{r}}{m} \\
H_{e q}=\sum_{i=1}^{m} H_{i}, K_{e q}=\sum_{i=1}^{m} K_{i}, D_{e q}=\sum_{i=1}^{m} D_{i}
\end{array}\right.
$$

In which the subscript $i$ is the serial number of each wind turbine, eq is the equivalent parameters, $m$ is the total number of equivalent units, and $H, K$, and $D$ respectively represent the inertial time constant, the shafting stiffness coefficient, and the shafting damping coefficient of the wind turbine.

Figure 2. Overall control system scheme of DFIG.

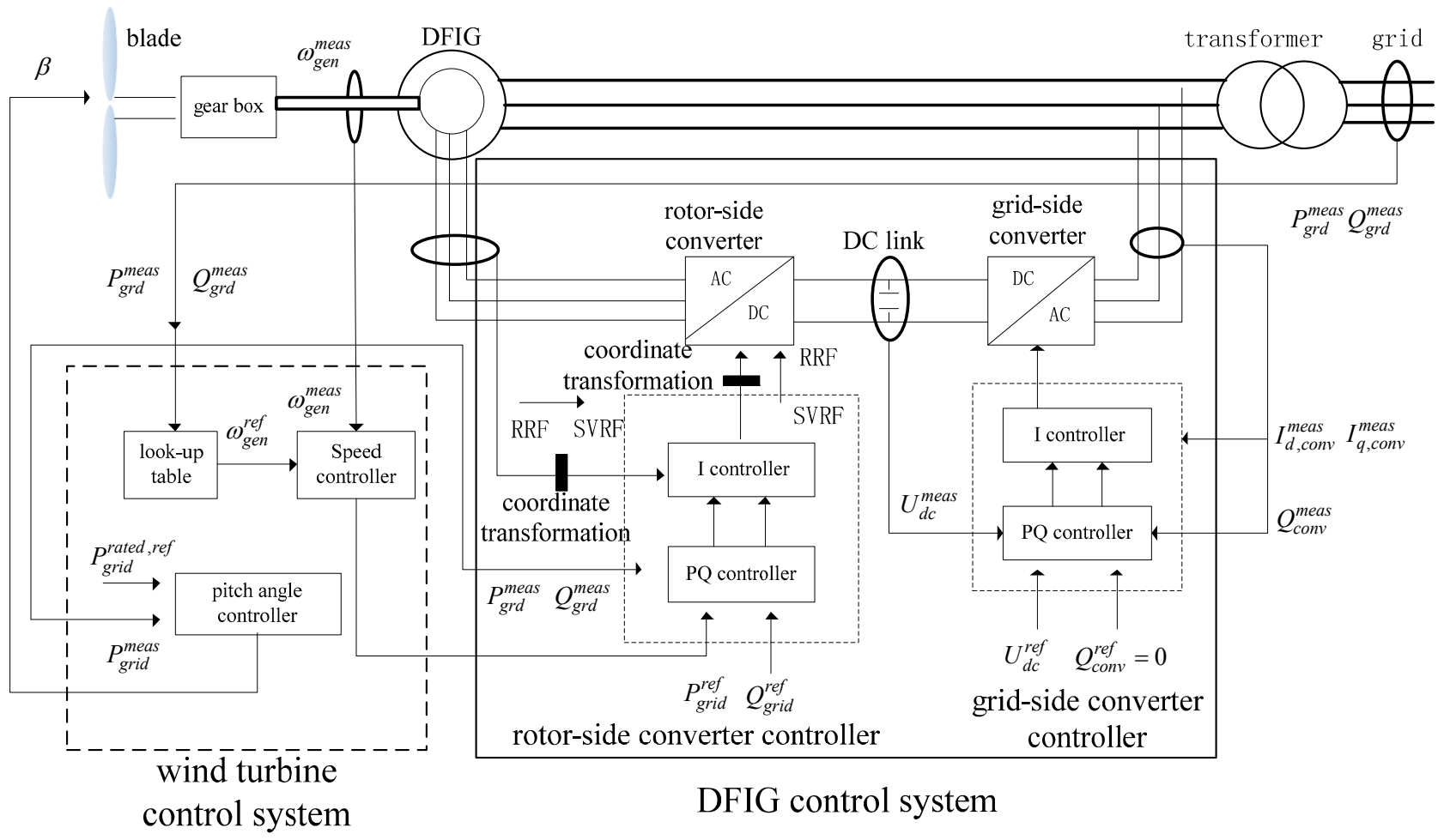




\section{Research on the Impact of Large-Scale Wind Power Integration on Small Signal Stability}

\subsection{The Simulation System}

At present, the equivalent wind farm is often used to represent the large-scale wind power integration. We can adjust the output of the wind farm to reflect different integration scales of wind power. In order to make this paper's research universal, the wind farm is integrated into the single-machine infinite-bus system through lines, as shown in Figure 3.

Figure 3. Large-scale wind farm integrated into SMIB.

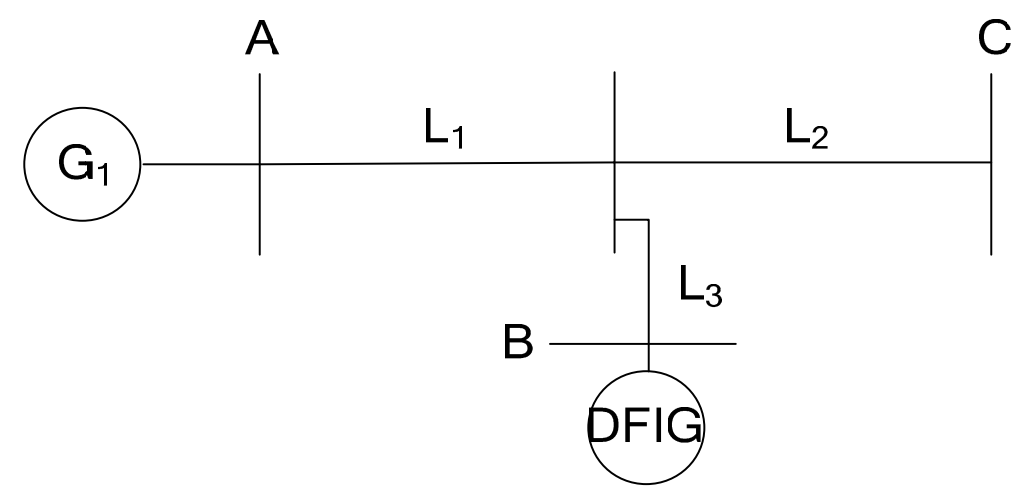

In Figure 3, bus $\mathrm{C}$ is the infinite bus, bus $\mathrm{A}$ is a PV node which connects to the conventional generator $\mathrm{G}_{1}$ with excitation system, and bus B is a PQ node which connects to the DFIG wind farm with the capacity of 210MVA. In the analysis, the wind farm is equivalent to one machine. The parameters of one signal wind turbine are shown in Table 1 . The excitation system of generator unit $\mathrm{G}_{1}$ adopts the A-type exciter in Appendix D of reference [29]. Parameters of power generation unit $\mathrm{G}_{1}$ and the excitation system are shown in Tables 2 and 3.

Table 1. DFIG parameters.

\begin{tabular}{cccccccccc}
\hline $\mathbf{P}_{\mathbf{n}}(\mathbf{M W})$ & $\mathbf{U}_{\mathbf{s}}(\mathbf{V})$ & $\mathbf{R}_{\mathbf{s}}(\mathbf{p . u})$ & $\mathbf{X}_{\mathbf{s}}(\mathbf{p} . \mathbf{u})$ & $\mathbf{X}_{\mathbf{m}}(\mathbf{p . u})$ & $\mathbf{R}_{\mathbf{r}}(\mathbf{p . u})$ & $\mathbf{X}_{\mathbf{r}}(\mathbf{p} . \mathbf{u})$ & $\mathbf{H}_{\mathbf{t}}(\mathbf{s})$ & $\mathbf{H}_{\mathbf{g}}(\mathbf{s})$ & $\mathbf{K}_{\mathbf{s}}$ \\
\hline 2 & 690 & 0.01 & 0.1 & 3.5 & 0.01 & 0.1 & 4.02 & 0.47 & 80.27 \\
\hline
\end{tabular}

Table 2. Generator parameters of $\mathrm{G}_{1}$.

\begin{tabular}{cccccccc}
\hline Capacity (MVA) & Voltage(KV) & $\mathbf{x}_{\mathbf{d}}(\mathbf{p} . \mathbf{u})$ & $x_{d}^{\prime}(p . u)$ & $\mathbf{x}_{\mathbf{q}}(\mathbf{p . u})$ & $x_{q}^{\prime}(p . u)$ & $T_{d 0}^{\prime}(s)$ & $T_{q 0}^{\prime}(s)$ \\
\hline 300 & 18 & 1.72 & 1.66 & 0.23 & 0.378 & 0.8 & 0.12 \\
\hline
\end{tabular}

Table 3. Excitation parameters.

\begin{tabular}{cccccccccccccc}
\hline $\boldsymbol{\tau}_{\mathbf{R}}$ & $\boldsymbol{\tau}_{\mathbf{A} 1}$ & $\mathbf{K}_{\mathbf{A}}$ & $\boldsymbol{\tau}_{\mathbf{A} 2}$ & $\mathbf{V}_{\mathbf{R m a x}}$ & $\mathbf{V}_{\mathbf{R m i n}}$ & $\boldsymbol{\tau}_{\mathbf{E}}$ & $\mathbf{K}_{\mathbf{E}}$ & $\mathbf{K}_{\mathbf{F}}$ & $\boldsymbol{\tau}_{\mathbf{F}}$ & $\mathbf{E 1}$ & $\mathbf{S e 1}$ & $\mathbf{E 2}$ & $\mathbf{S e 2}$ \\
\hline 0.06 & 0.2 & 0.001 & 0.01 & 3 & -3 & 0.5 & -0.044 & 0.085 & 0.35 & 3.66 & 0.03 & 4.89 & 0.1 \\
\hline
\end{tabular}

In Table 2, the voltage and power reference values are this machine's rated voltage and capacity. Line type is LGJ-400, L1 of $100 \mathrm{~km}$ in length, L2 of $200 \mathrm{~km}$ in length, and L3 of $15 \mathrm{~km}$ in length.

The model was built using DIgSILENT/PowerFactory simulation software. 


\subsection{Impact of Wind Power Integration Scale}

This paper substitutes the constant power source, synchronous generator and synchronous generator with an excitation system of the same capacity for the wind farm in Figure 3, studying the impact of the scale of the wind power integration on small signal stability through the comparison of small signal stability region boundaries. The formation of a small signal stability region boundary is obtained by the method in Section 2. In this study, we mark the active power output of generator $\mathrm{G}_{1}$ as $P_{1}$, the DFIG and its corresponding substitute power source's active power output as $P_{2}$, and synchronous generator, which replaced the power supply, as $\mathrm{G}_{2}$, whose parameters are shown in Table 4. The Hopf bifurcation sampling points are shown in Appendix A.

Table 4. Generator parameters of $\mathrm{G}_{2}$.

\begin{tabular}{cccccccc}
\hline Capacity(MVA) & Voltage(KV) & $\mathbf{x}_{\mathbf{d}}(\mathbf{p . u})$ & $x_{d}^{\prime}(p . u)$ & $\mathbf{x}_{\mathbf{q}}(\mathbf{p . u})$ & $x_{q}^{\prime}(p . u)$ & $T_{d 0}^{\prime}(s)$ & $T_{q 0}^{\prime}(s)$ \\
\hline 210 & 18 & 2.642 & 2.346 & 0.337 & 0.557 & 0.635 & 0.453 \\
\hline
\end{tabular}

\subsubsection{Contrast between Wind Farm and Constant Power Source}

According to Tables A1 and A2 in the Appendix A, the small signal stability region boundary contrast between a wind farm and a constant power source when they connect to the power system is shown in Figure 4.

Figure 4. The stability region boundary contrast between wind farm and constant power source.

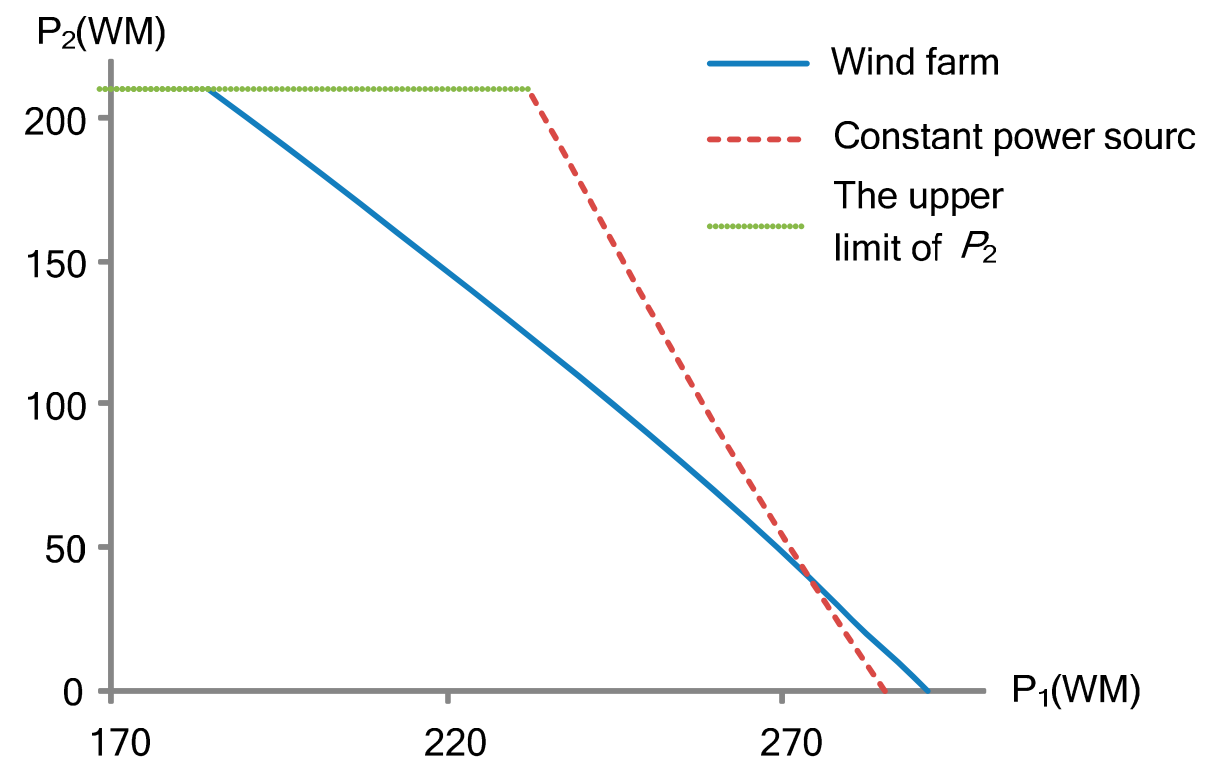

As can be seen from Figure 4, the stability region boundaries cross over when the wind farm and constant power source connect to the power system. Below the crossover point, namely when the wind power integration scale is relatively small, the stability region boundary of the wind farm is higher than that of the constant power source, suggesting that the small signal stability of wind farm integration is better than that of constant power source integration. However, above the crossover point, namely when the wind power integration scale is relatively large, the stability region boundary of the wind farm is 
lower than that of the constant power source, suggesting that the small signal stability of wind farm integration is worse than that of constant power source integration.

In order to further validate the argument, we selected two operating points of the power system: point $1(220,180)$ and point $2(276.7,30)$, which are both located in the region surrounded by the two boundaries. Point 1 is above the crossover point, while point 2 is below the crossover point. The method of time-domain simulation was adopted to compare the small signal stability between wind power integration and constant power source integration. The small disturbance was set as the mechanical torque's increasing $0.01 \mathrm{p}$.u of generator $\mathrm{G}_{1}$ at $1 \mathrm{~s}$, then restored to the original level at $2 \mathrm{~s}$. The simulation time was set at $20 \mathrm{~s}$. This resulted in the power angle swing curves shown in Figures 5 and 6.

As can be seen from Figure 5, when the power system operates at point 1, generator G1's power angle oscillation amplitude will become bigger and bigger with wind farm integration under small disturbance, making the system eventually lose stability. On the other hand, when the constant power source is integrated into the power system, generator $\mathrm{G}_{1}$ 's power angle oscillation amplitude will become smaller and smaller and ultimately tends to be stable. However, Figure 6 shows that when the power system operates at point 2, generator G1's power angle oscillation amplitude will decrease slowly with wind farm integration under small disturbance; when the constant power source is integrated into the power system, generator $\mathrm{G}_{1}$ 's power angle is almost in constant amplitude oscillation. The contrast is not very obvious because the region below the crossover point is small and the operating point 2 is close to both instability boundaries. Therefore, the difference between the two stable levels is not obvious. The simulation results of Figures 5 and 6 verify this section's conclusion.

Figure 5. The angle swing curves when the system is at operation point 1.

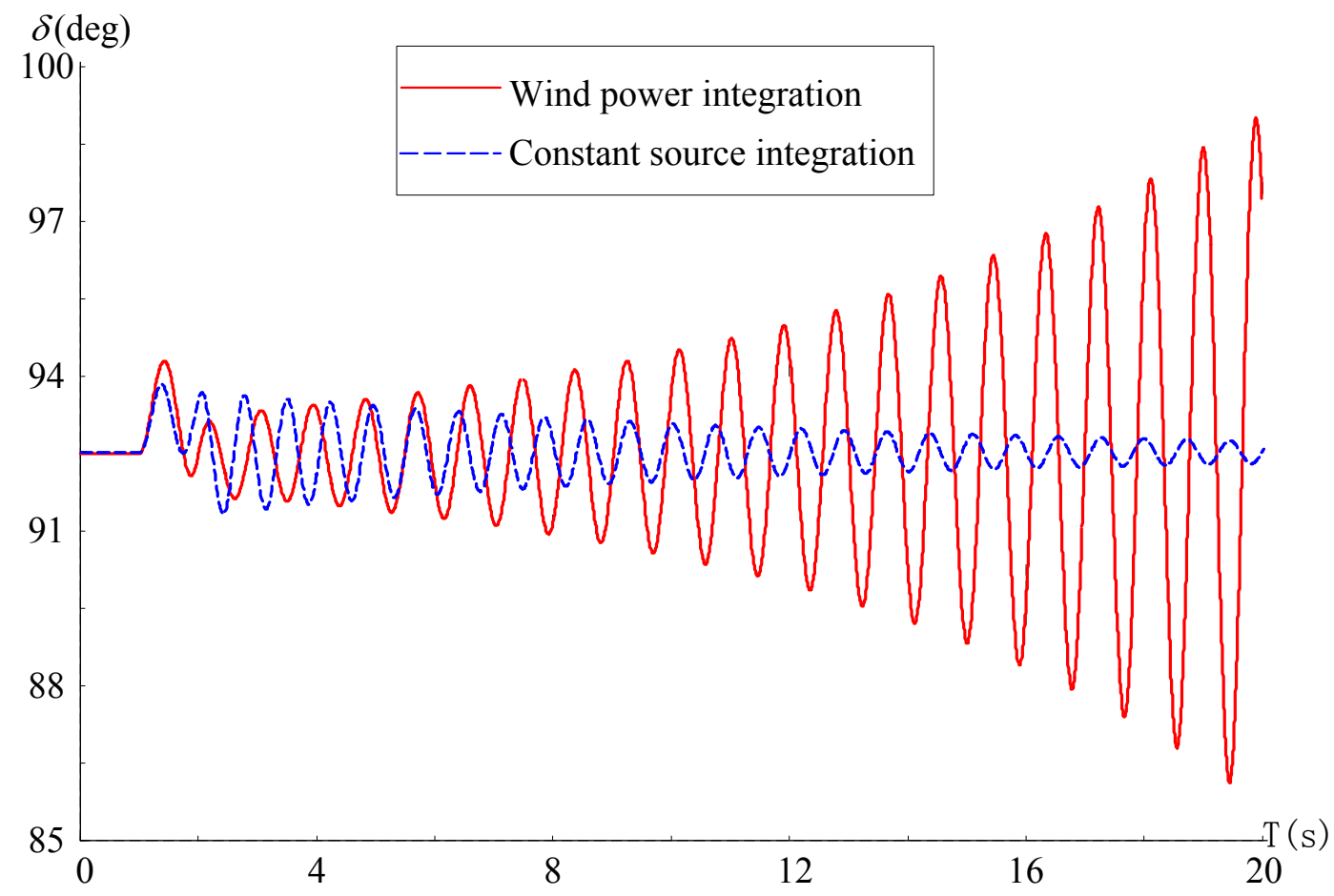


Figure 6. The angle swing curves when the system is at operation point 2.

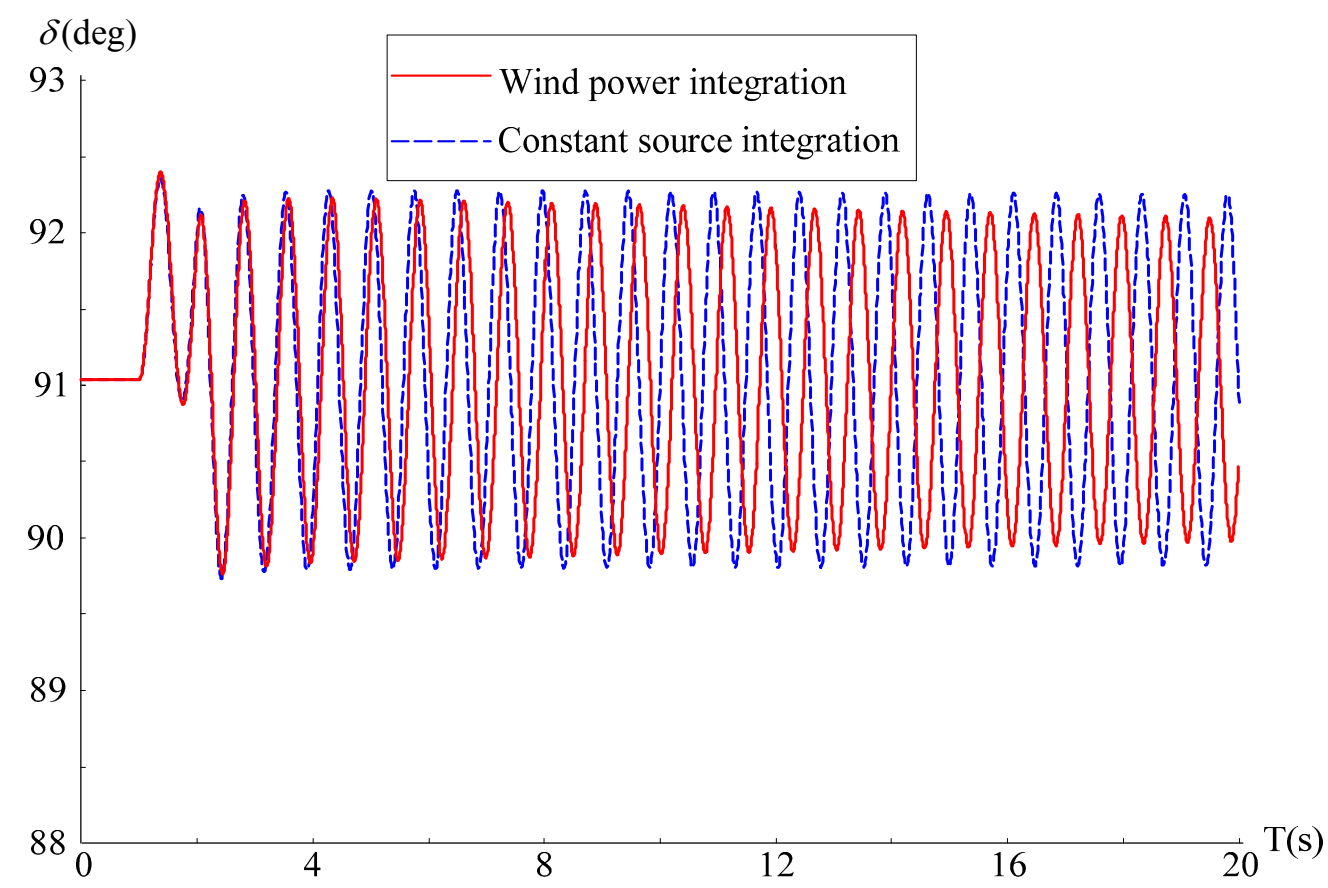

\subsubsection{Contrast between Wind Farm and Conventional Generator}

In this Section, the synchronous generator $\mathrm{G}_{2}$ with the same capacity was used to substitute for the wind farm. In the range of power flow equations that have solutions, the system is always stable, with small disturbance. In the meantime, the small signal stability region boundary consists of the boundary of power flow equations that have solutions and the upper output limit of the power source. The detailed boundary sampling points refer to Table A3 in the Appendix.

According to Tables A1 and A3 in the Appendix A, the small signal stability region boundary contrast between wind farms and synchronous generators when they connect to the power system is shown in Figure 7.

Figure 7. The stability region boundary contrast between wind farm and synchronous machine.

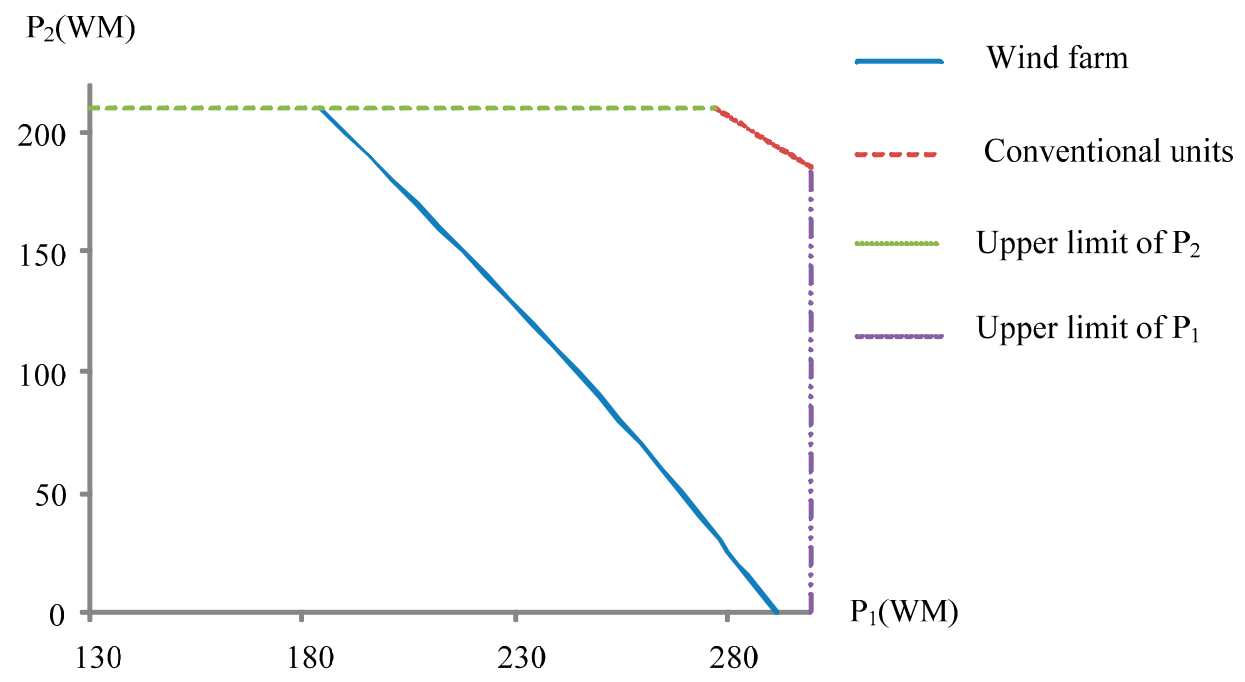


As can be seen from Figure 7, when the wind farm replaces the conventional generators, the small signal stability region boundary is greatly narrowed and the power system small signal stability is reduced.

Operating point $3(260,120)$ is located in the region surrounded by the two boundaries. The same method of time-domain simulation was adopted to validate the argument. The set value of the small disturbance remained unchanged. This resulted in the power angle swing curves shown in Figure 8.

As can be seen from Figure 8, when the power system operates at point 3, generator G1's power angle oscillation amplitude will become bigger and bigger with wind farm integration under small disturbance, making the system eventually lose stability. By contrast, when the constant power source is integrated into the power system, generator G1's power angle oscillation amplitude will become smaller and smaller, ultimately tending to be stable. The simulation results verify this section's conclusion.

Figure 8. The angle swing curves when the system is at operation point 3.

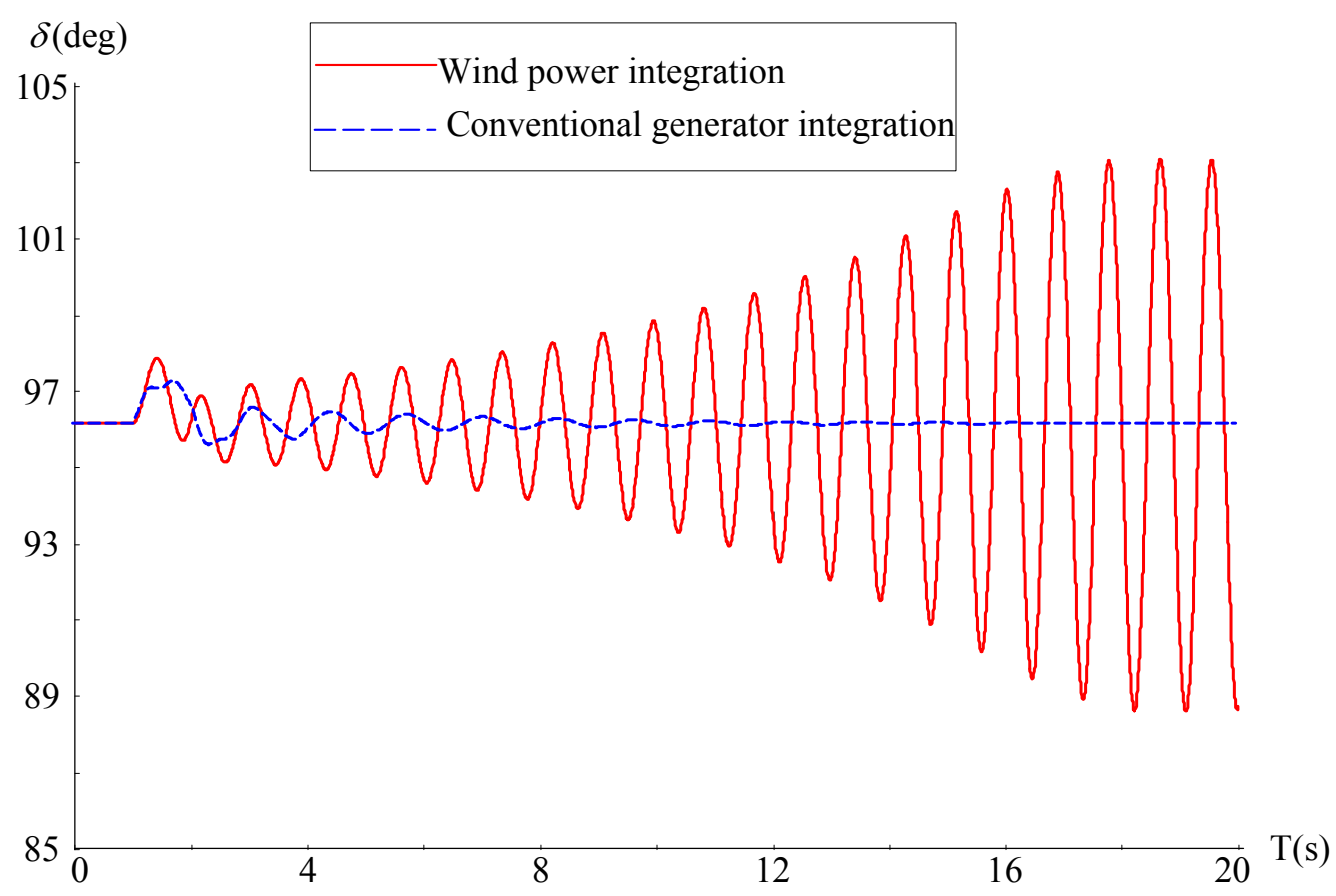

4.2.3. Contrast between Wind Farm and Synchronous Generator with Excitation System

According to Tables A1 and A4 in the Appendix A, the stability region boundary contrast between a wind farm and a synchronous generator with excitation system when they connect to the power system is shown in Figure 9.

As can be seen from Figure 9, the stability region boundaries also cross over each other when the wind farm and the conventional generator with excitation system connect to the power system. However, these circumstances are contrary to Figure 4. Below the crossover point, namely when the wind power integration scale is relatively small, the stability region boundary of the wind farm is lower than that of the synchronous generator with excitation system, suggesting that the small signal stability of wind farm integration is worse than that of a synchronous generator with excitation system. Above the crossover point, namely when the wind power integration scale is relatively large, the stability region boundary of the wind farm is higher than that of the synchronous generator with excitation system, suggesting that the small signal stability of wind farm integration is better than that of a synchronous generator with excitation system. 
Figure 9. The stability region boundary contrast between wind farm and synchronous generator with excitation system.

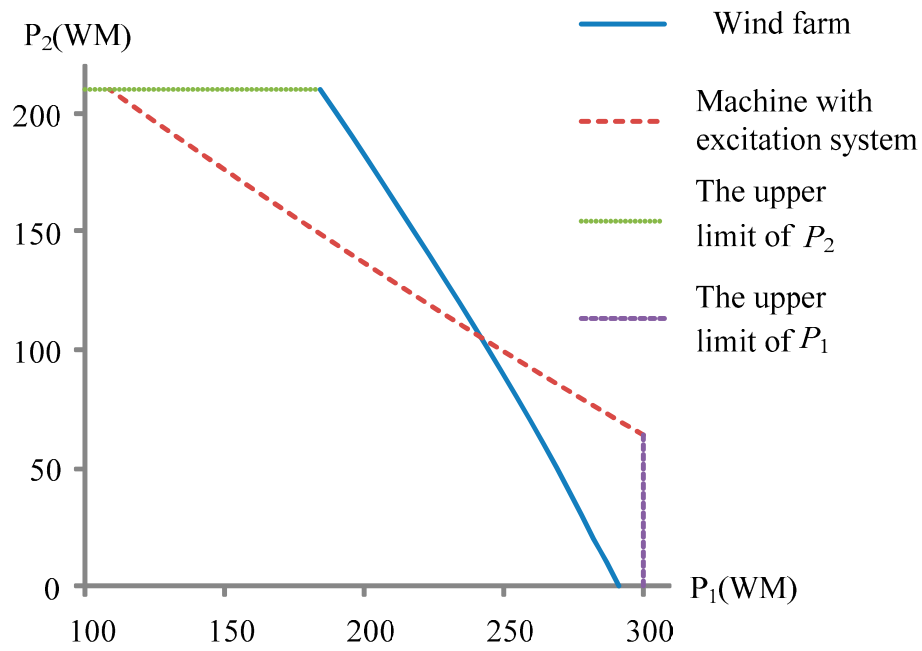

We selected two operating points, point $4(180,180)$ and point $5(278,60)$, and adopted the same method of time-domain simulation to validate the argument. Point 4 is above the crossover point and Point 5 is below the crossover point; both are located in the region surrounded by the two boundaries. The set value of the small disturbance remains unchanged. This resulted in the power angle swing curves shown in Figures 10 and 11.

As can be seen from Figure 10, when the power system operates at point 4 with wind power integration under small disturbance, generator G1's power angle oscillation amplitude will become smaller and smaller, ultimately tending to be stable. By contrast, when the synchronous generator with excitation system is integrated into the power system, generator $\mathrm{G}_{1}$ 's power angle oscillation amplitude will become bigger and bigger under small signal, making the system eventually lose stability. The results in Figure 11 are just the opposite and thus verify the correctness of this section's conclusion.

Figure 10. The angle swing curves when the system is at operation point 4 .

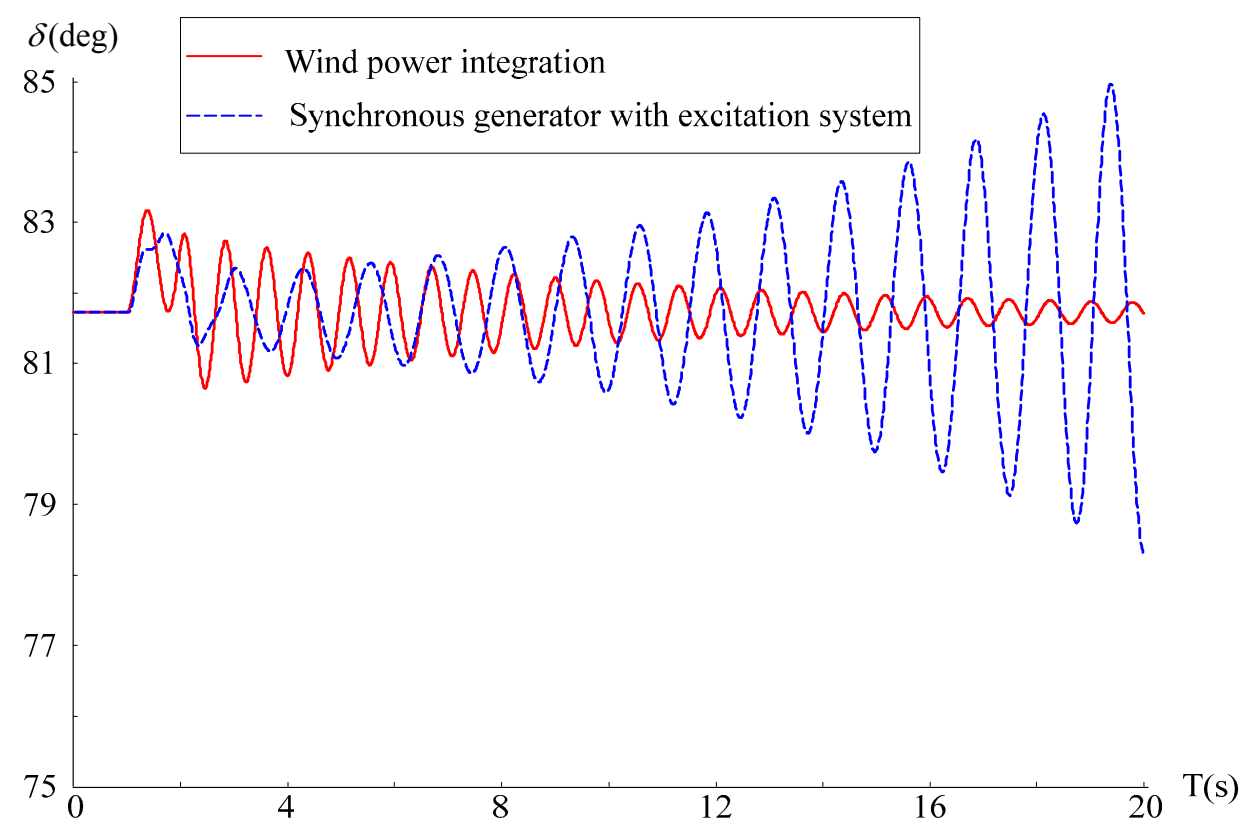


Figure 11. The angle swing curves when the system is at operation point 5.

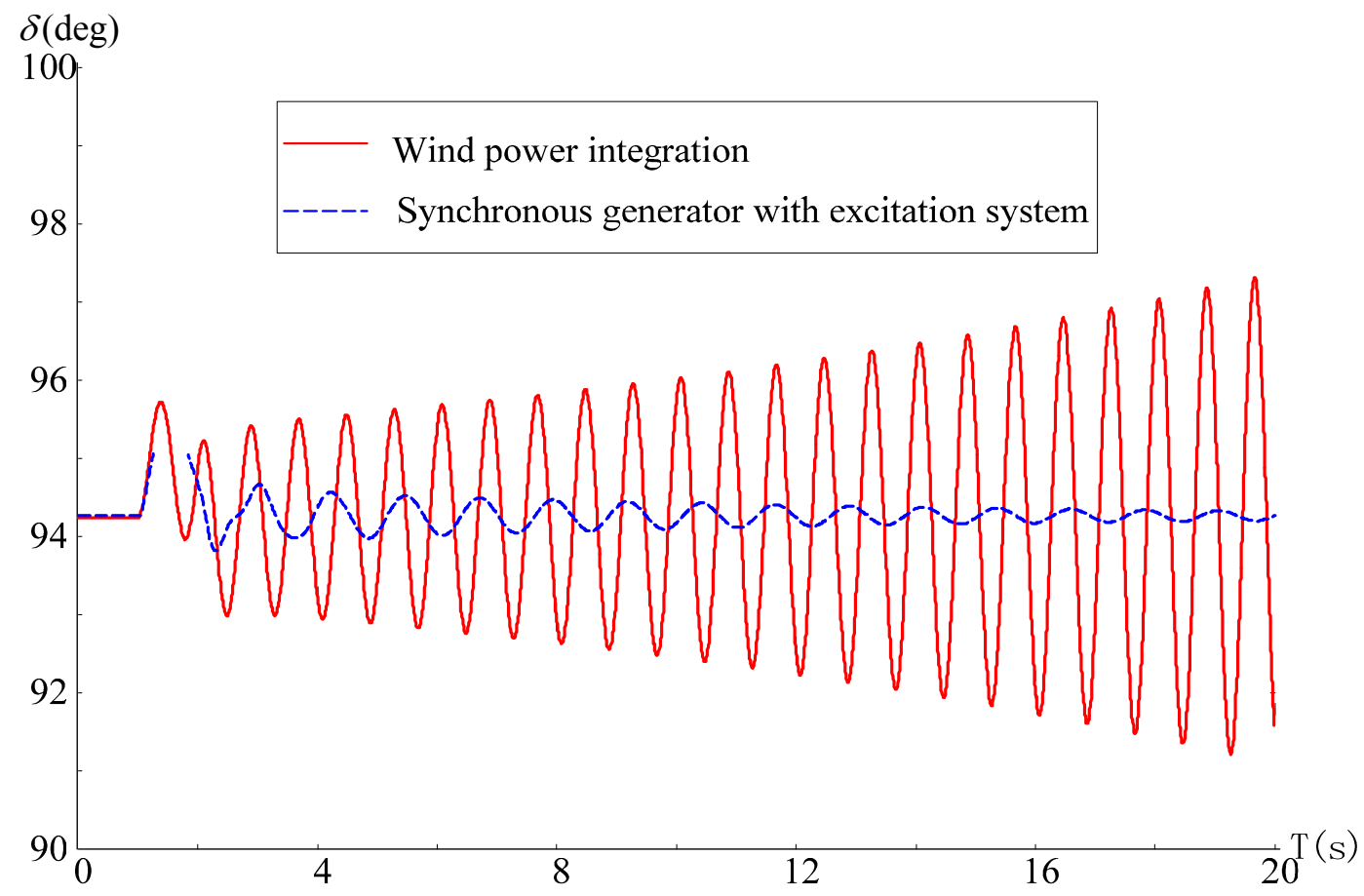

\subsubsection{Summary}

The above analyses show that, in terms of small signal stability, compared with a constant power source, synchronous generator, and synchronous generator with excitation system, a wind farm shows significant differences. For a fixed power grid structure, wind power integration does not always increase or decrease the small signal stability of the power system, depending on the scale of wind power integration and the contrast power source type.

\subsection{Impact of the Coupling Strength of Wind Power and Synchronous Generators on Small Signal Stability}

At present, especially in China, large-scale wind power is often transmitted by way of wind-thermal-bundled power transmission [30] (Gao. et al., 2013). The coupling strength of wind power and conventional units has become an important factor affecting power system small signal stability. This section mainly analyzes this subject. As shown in Figure 3, when line $\mathrm{L}_{1}$ is longer, this indicates that the coupling strength between wind power and conventional units is weaker. Thus the length of $\mathrm{L}_{1}$ is adjusted to describe different coupling strengths; in this case, the total length of lines $\mathrm{L}_{1}$ and $\mathrm{L}_{2}$ remains unchanged. We set the length of line $\mathrm{L}_{1}$ to be $50 \mathrm{~km}, 150 \mathrm{~km}$, and $200 \mathrm{~km}$, respectively, and obtained the sampling points of small signal stability region boundary as shown in Tables A5-A7 in Appendix B.

A comparison of these stability region boundaries is given in Figure 12. The number after the legend represents the length of line $\mathrm{L}_{1}$ in $\mathrm{km}$. 
Figure 12. The stability region boundary of small-signal stability under different lengths of $\mathrm{L}_{1}$.

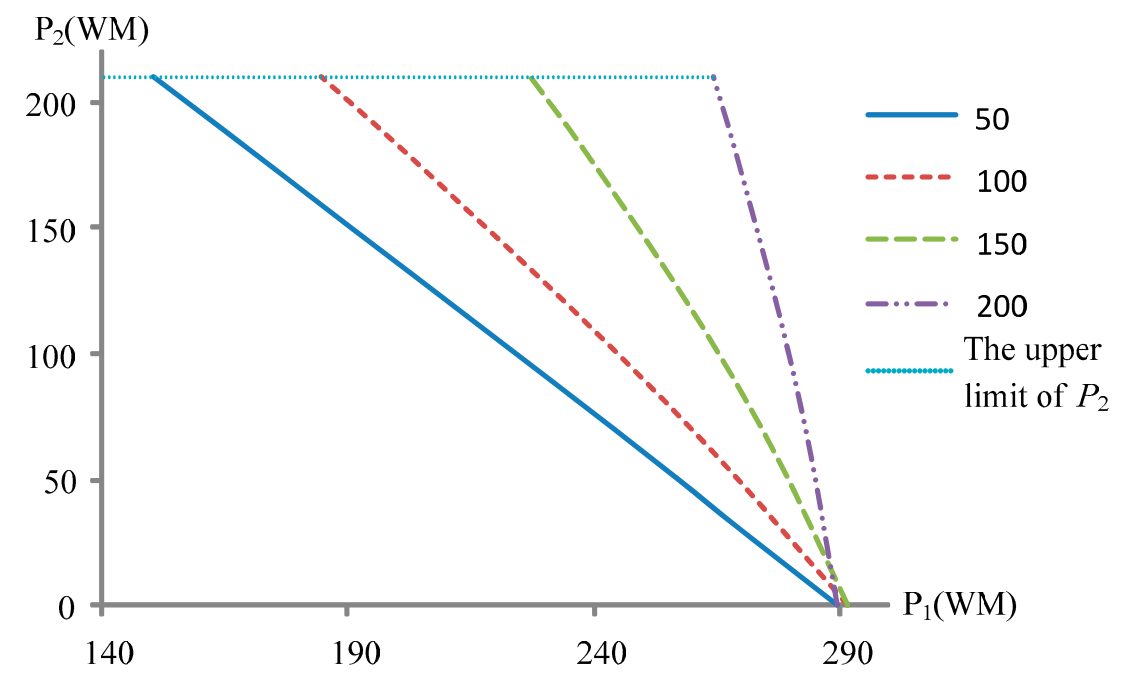

As can be seen from Figure 12, the smaller the distance between the wind power and synchronous generator, the stronger the coupling effect between them. Also, the further to the lower left the border line drifts, the smaller the corresponding stable region and the worse the small signal stability.

In order to further validate the argument in this section, we set $\mathrm{L}_{1}$ at $50 \mathrm{~km}$ and $200 \mathrm{~km}$ and chose operating point $6(210,150)$, which is located in the region surrounded by the two boundaries. The same method of time-domain simulation was adopted to validate the argument. The set value of the small disturbance remained unchanged. This resulted in the power angle swing curves shown in Figure 13.

Figure 13. The angle swing curves when the system is at operation point 6 .

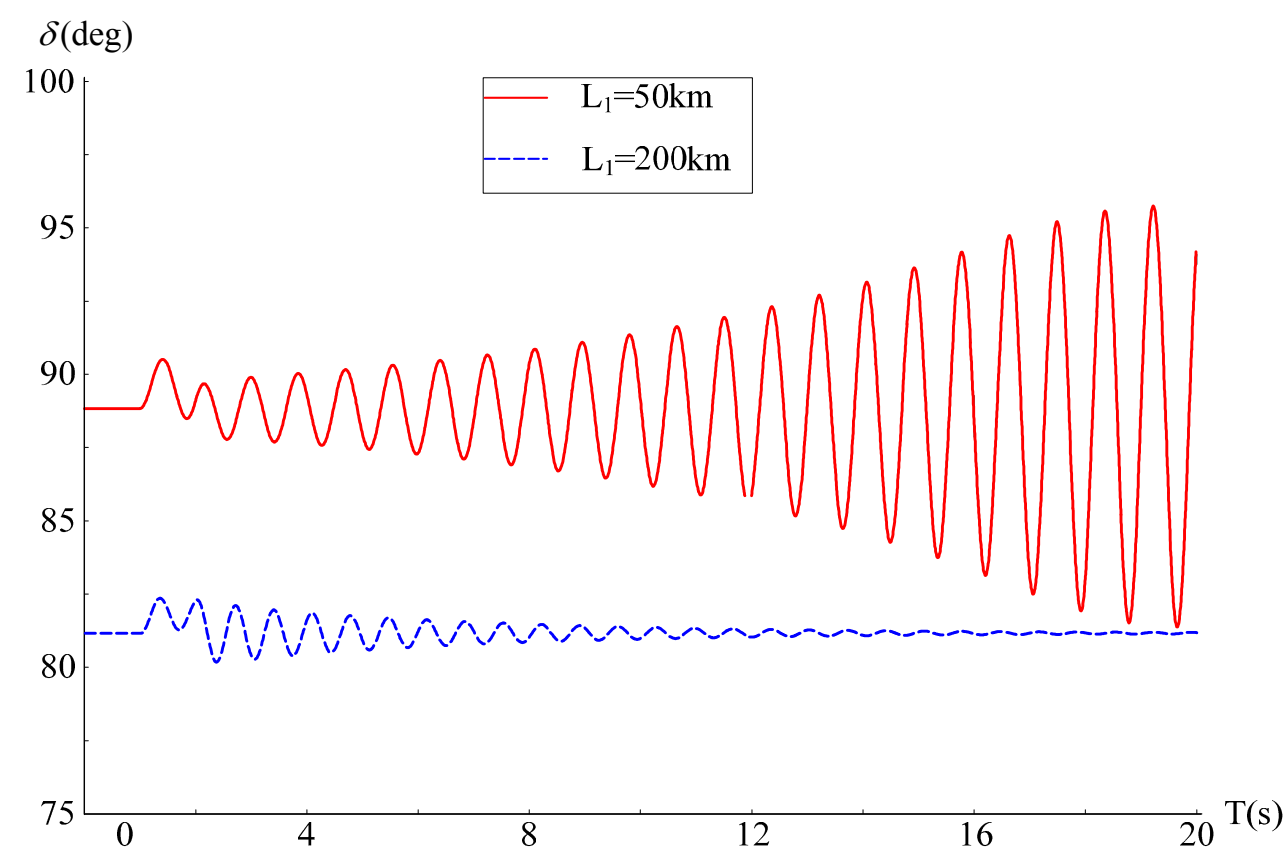

As can be seen from Figure 13, when the power system operates at point 6, generator G1's power angle oscillation amplitude will become bigger and bigger when $\mathrm{L}_{1}=50 \mathrm{~km}$, making the system eventually lose stability. On the other hand, when $\mathrm{L}_{1}=200 \mathrm{~km}$, generator $\mathrm{G}_{1}$ 's power angle oscillation 
amplitude will become smaller and smaller, ultimately tending to be stable. The simulation results in time-domain verify the correctness of this section's conclusion.

\section{Discussion with Respect to Existing Research Results}

Based on the conclusions above, this paper attempts to discuss the results of some of the published literature through comparison. As noted above, the results of previous studies are often in conflict. The reason is that most of these studies are based on a certain grid and typical working conditions, which study the impact of different integration scales of wind power on small signal stability by replacing the conventional units with wind turbines.

The published papers often use wind turbines as substitutes for the synchronous machine with excitation system to study the power system small signal stability with wind power integration, only changing the power output of the wind turbine and its substitute conventional units, i.e., keeping $P$ fixed and only changing $P_{2}$ in Figure 9 . We labeled the intersection point of the small signal stability boundary lines as point $\mathrm{A}$, whose $P_{1}$ is $P_{1}$. We then redrew it to create Figure 14.

Figure 14. The research contrast between this article and the published papers.

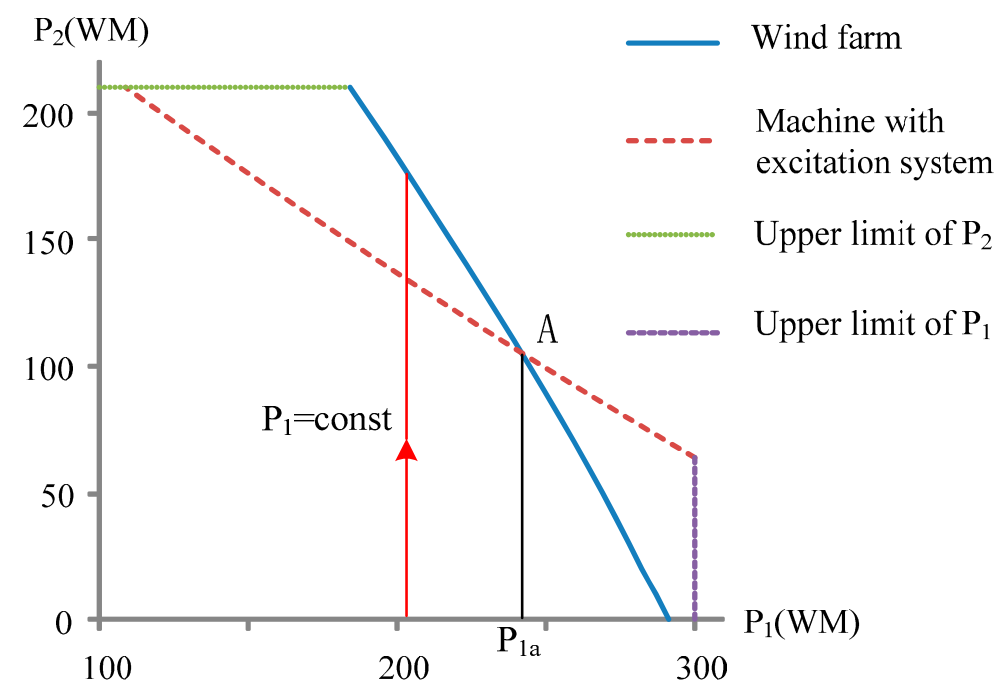

Different working conditions correspond to different sizes of $P_{1}$, which means the line $P_{1}=$ const is at different positions on the horizontal axis. Based on previous analyses, we got that when $P_{1}<P_{1}$, wind power integration would improve power system small signal stability, which corresponds to the conclusions of reference [11,12]; and that when $P_{1}>P_{1 \text { a, }}$, wind power would reduce power system small signal stability, which corresponds to the conclusions of reference [15-17]. When the size of $P_{1}$ and $P_{1}$ is close, the impact of wind power on small signal stability would be very small, which corresponds to the conclusions of reference $[13,14]$.

Therefore, although the conclusions of the current literature seem to be contradictory, they in fact only reflect a part of the grid. Analysis based on small signal stability boundary offered a good interpretation from a qualitative point of view. 


\section{Conclusions}

Compared with the traditional research method of grid-connected wind power, the small signal stability region boundary approach provides a broader perspective. Based on wind farm integration coupled with a single-machine infinite-bus system, this paper draws the following conclusions:

(1) Compared with the constant power source: when the wind power integration scale is relatively small, the small signal stability of wind farm integration is better than that of constant power source integration; when the wind power integration scale is relatively large, the small signal stability of wind farm integration is worse than that of constant power source integration.

(2) Compared with the synchronous generator, a wind farm greatly reduces the small signal stability region boundary and the small signal stability of the power system.

(3) Compared with the synchronous generator with excitation system: when the wind power integration scale is relatively small, the small signal stability of wind farm integration is worse than that of a synchronous generator with excitation system integration; when the wind power integration scale is relatively large, the small signal stability of wind farm integration is better than that of synchronous generator with excitation system integration.

(4) The stronger the wind farm coupling with the synchronous generator, the worse the small signal stability is.

This paper presents a way of analyzing the impact of wind power integration on small signal stability. The results qualitatively explain why current research results often contradict each other. However, this paper still has some limitations. As with the previous studies, the essence of this paper is still based on simulation, making conclusions from a qualitative perspective; there is thus a lack of in-depth study on the mechanisms of small signal stability with wind integration. This will be the further research direction.

\section{Acknowledgments}

This work is supported by the project "Research of the Impact Mechanism on Self-organized Critical State by Large-scale Cluster Grid-connected Wind Power and Identification", funded by the National Science Foundation of China (51377053), and the project "The Research of Key Techniques of Loss Reduction in Power System Based on Load-Net-Source Coordinated Control," funded by Major Project of State Grid Corporation of China (52272214002).

\section{Author Contributions}

Wenying Liu contributed to design, directed, and made suggestions for the research. Rundong Ge contributed to analysis, writing, and interpretation of the research. Huiyong Li translated this article from Chinese to English. Jiangbei Ge made suggestions for the research. All co-authors contributed to the writing of the final research article.

\section{Appendix}

This article has two Appendixes: Appendix A; Appendix B. 


\section{Appendix $A$}

Adopt the power system shown in Figure 3 and maintain the length of line $\mathrm{L}_{1}$ at $100 \mathrm{~km}$, the length of line $\mathrm{L}_{2}$ at $200 \mathrm{~km}$, and the wind farm capacity at $210 \mathrm{MVA}$.

Appendix A1 Sampling points of small signal stability region boundary with wind farm integration.

Adjust unit $\mathrm{G}_{1}$ and the wind farm output $P_{1}, P_{2}$ until the real part of the eigenvalue of the system is 0 . Data points collected are shown in Table A1.

Table A1. The boundary points of small-signal stability region with wind power integration.

\begin{tabular}{cccc}
\hline $\boldsymbol{P}_{\mathbf{1}}(\mathbf{M W})$ & $\boldsymbol{P}_{\mathbf{2}}(\mathbf{M W})$ & Real Part & Imaginary Part \\
\hline 287.19 & 10 & -0.00001 & 8.307174 \\
282.42 & 20 & 0 & 8.238311 \\
278.15 & 30 & 0 & 8.248987 \\
273.78 & 40 & 0 & 8.21387 \\
269.24 & 50 & -0.00001 & 8.179261 \\
264.57 & 60 & 0.00001 & 8.14443 \\
259.76 & 70 & 0 & 8.109634 \\
254.85 & 80 & 0 & 8.074076 \\
249.84 & 90 & 0.00001 & 8.037758 \\
244.73 & 100 & 0 & 8.000639 \\
239.54 & 110 & 0 & 7.962331 \\
234.27 & 120 & -0.00001 & 7.922771 \\
228.93 & 130 & 0 & 7.881692 \\
223.51 & 140 & -0.00002 & 7.839274 \\
218.03 & 150 & 0 & 7.794989 \\
212.53 & 160 & 0.00001 & 7.747845 \\
207.09 & 170 & 0 & 7.695774 \\
201.56 & 180 & -0.00002 & 7.642112 \\
195.95 & 190 & 0.00002 & 7.586527 \\
190.23 & 200 & 0 & 7.529779 \\
184.42 & 210 & 0.00002 & 7.47128 \\
\hline
\end{tabular}

Appendix A2 Sampling points of small signal stability region boundary when a constant power source substitutes for the wind farm.

Adopt the constant power source with the same capacity to substitute for the wind farm, adjust unit $\mathrm{G}_{1}$ and the constant power source output $P_{1}, P_{2}$ until the real part of the eigenvalue of the system is 0 . Data points collected are shown in Table A2.

Table A2. The boundary points of small-signal stability region with constant power source integration.

\begin{tabular}{cccc}
\hline $\boldsymbol{P}_{\mathbf{1}}(\mathbf{M W})$ & $\boldsymbol{P}_{\mathbf{2}}(\mathbf{M W})$ & Real Part & Imaginary Part \\
\hline 285.15 & 0 & 0 & 8.473956 \\
282.22 & 10 & 0 & 8.477754 \\
279.34 & 20 & 0 & 8.48028 \\
276.51 & 30 & 0 & 8.481479 \\
\hline
\end{tabular}


Table A2. Cont.

\begin{tabular}{cccc}
\hline $\boldsymbol{P}_{\mathbf{1}}(\mathbf{M W})$ & $\boldsymbol{P}_{\mathbf{2}}(\mathbf{M W})$ & Real Part & Imaginary Part \\
\hline 273.74 & 40 & 0.00004 & 8.481118 \\
271 & 50 & 0 & 8.479654 \\
268.32 & 60 & 0 & 8.476482 \\
265.69 & 70 & 0.00001 & 8.471689 \\
263.1 & 80 & 0 & 8.46534 \\
260.56 & 90 & 0 & 8.45716 \\
258.06 & 100 & -0.00001 & 8.447184 \\
255.61 & 110 & 0.00001 & 8.43507 \\
253.18 & 120 & -0.00002 & 8.421195 \\
250.8 & 130 & 0.00001 & 8.40478 \\
248.43 & 140 & -0.00001 & 8.38634 \\
246.09 & 150 & 0 & 8.365192 \\
243.76 & 160 & 0 & 8.341377 \\
241.44 & 170 & 0.00001 & 8.314462 \\
239.11 & 180 & 0.00002 & 8.283348 \\
236.75 & 190 & -0.00002 & 8.250802 \\
234.37 & 200 & 0 & 8.21279 \\
231.93 & 210 & 0 & 8.170178 \\
\hline
\end{tabular}

Appendix A3 Sampling points of small signal stability region boundary with synchronous generator integration.

Adopt the synchronous generator with the same capacity to substitute for the wind farm. In the range of power flow equations that have solutions, the eigenvalues which are far away from the imaginary axis reflect strong damping. Thus we regard the boundary of power flow equations that have solutions as the small signal stability region boundary. Data points collected are shown in Table A3.

Table A3. The boundary points of small signal stability region with conventional units.

\begin{tabular}{cccc}
\hline $\boldsymbol{P}_{\mathbf{1}}(\mathbf{M W})$ & $\boldsymbol{P}_{\mathbf{2}}(\mathbf{M W})$ & Real Part & Imaginary Part \\
\hline 276.89 & 210 & -1.08264 & 10.97483 \\
281.52 & 205 & -1.07955 & 10.92772 \\
286.15 & 200 & -1.07566 & 10.86845 \\
290.76 & 195 & -1.0751 & 10.8334 \\
295.38 & 190 & -1.07258 & 10.77569 \\
300 & 185 & -1.06955 & 10.7081 \\
\hline
\end{tabular}

Appendix A4 Sampling points of small signal stability region boundary with synchronous generator integration with excitation system.

Apply the same excitation system to generator $\mathrm{G}_{2}$ as used in generator $\mathrm{G}_{1}$. Adjust the power output $P_{1}, P_{2}$ of units $\mathrm{G}_{1}, \mathrm{G}_{2}$ until the real part of the eigenvalue of the system is 0 . Data points collected are shown in Table A4. 
Table A4. The boundary points of small signal stability region with synchronous generator integration with exciter.

\begin{tabular}{cccc}
\hline $\boldsymbol{P}_{\mathbf{1}}(\mathbf{M W})$ & $\boldsymbol{P}_{\mathbf{2}}(\mathbf{M W})$ & Real Part & Imaginary Part \\
\hline 300 & 63.71 & -0.00002 & 4.905703 \\
290.88 & 70 & -0.00002 & 4.936389 \\
276.6 & 80 & 0.00001 & 4.981546 \\
262.56 & 90 & 0.00001 & 5.022762 \\
248.75 & 100 & -0.00001 & 5.060383 \\
235.18 & 110 & 0 & 5.094568 \\
221.81 & 120 & 0 & 5.125803 \\
208.63 & 130 & 0 & 5.154317 \\
195.63 & 140 & 0 & 5.180313 \\
182.8 & 150 & 0 & 5.203976 \\
170.12 & 160 & 0 & 5.225517 \\
157.58 & 170 & 0 & 5.245079 \\
145.18 & 180 & 0 & 5.262717 \\
132.92 & 190 & 0.00001 & 5.278452 \\
120.77 & 200 & -0.00001 & 5.292524 \\
108.87 & 210 & 0.00001 & 5.304092 \\
\hline
\end{tabular}

Appendix B:

In this study, keep the wind farm capacity at 210MVA and the total length of lines $\mathrm{L}_{1}$ and $\mathrm{L}_{2} 300 \mathrm{~km}$. Appendix A5 Sampling points of small signal stability region boundary when the length of line $\mathrm{L}_{1}$ is $50 \mathrm{~km}$.

Set the length of line $\mathrm{L}_{1}$ to be $50 \mathrm{~km}$, adjust unit $\mathrm{G}_{1}$ and wind farm output $P_{1}, P_{2}$ until the real part of the eigenvalue of the system is 0 . Data points collected are shown in Table A5.

Table A5. The boundary points of small signal stability region when the length of $\mathrm{L}_{1}$ is $50 \mathrm{~km}$.

\begin{tabular}{cccc}
\hline $\boldsymbol{P}_{\mathbf{1}}(\mathbf{M W})$ & $\boldsymbol{P}_{\mathbf{2}}(\mathbf{M W})$ & Real Part & Imaginary Part \\
\hline 269.5 & 30 & -0.00001 & 8.291979 \\
256.86 & 50 & 0 & 8.230164 \\
243.8 & 70 & -0.00002 & 8.167506 \\
230.58 & 90 & 0.00001 & 8.101046 \\
217.25 & 110 & -0.00001 & 8.029631 \\
203.87 & 130 & 0.00001 & 7.951768 \\
190.43 & 150 & 0 & 7.867256 \\
177.14 & 170 & 0 & 7.770949 \\
163.82 & 190 & -0.00001 & 7.665956 \\
150.31 & 210 & 0.00001 & 7.555545 \\
\hline
\end{tabular}

Appendix A6 Sampling points of small signal stability region boundary when the length of line $\mathrm{L}_{1}$ is $150 \mathrm{~km}$.

Set the length of line $\mathrm{L}_{1}$ to be $150 \mathrm{~km}$, adjust unit $\mathrm{G}_{1}$ and wind farm output $P_{1}, P_{2}$ until the real part of the eigenvalue of the system is 0 . Data points collected are shown in Table A6. 
Table A6. The boundary points of small signal stability region when the length of $\mathrm{L}_{1}$ is $150 \mathrm{~km}$.

\begin{tabular}{cccc}
\hline $\boldsymbol{P}_{\mathbf{1}}(\mathbf{M W})$ & $\boldsymbol{P}_{\mathbf{2}}(\mathbf{M W})$ & Real Part & Imaginary Part \\
\hline 284.22 & 30 & 0 & 8.276686 \\
279.38 & 50 & 0.00002 & 8.218791 \\
274.03 & 70 & 0 & 8.160303 \\
268.26 & 90 & 0.00001 & 8.099242 \\
262.1 & 110 & 0.00001 & 8.034571 \\
255.57 & 130 & -0.0002 & 7.965255 \\
248.72 & 150 & 0.00002 & 7.889517 \\
241.73 & 170 & 0 & 7.802425 \\
234.5 & 190 & 0 & 7.704429 \\
226.84 & 210 & -0.0002 & 7.59843 \\
\hline
\end{tabular}

Appendix A7 Sampling points of small signal stability region boundary when the length of line $\mathrm{L}_{1}$ is $200 \mathrm{~km}$.

Set the length of line $\mathrm{L}_{1}$ to be $200 \mathrm{~km}$, adjust unit $\mathrm{G}_{1}$ and wind farm output $P_{1}, P_{2}$ until the real part of the eigenvalue of the system is 0 . Data points collected are shown in Table A7.

Table A7. The boundary points of small signal stability when the length of $L_{1}$ is $200 \mathrm{~km}$.

\begin{tabular}{cccc}
\hline $\boldsymbol{P}_{\mathbf{1}}(\mathbf{M W})$ & $\boldsymbol{P}_{\mathbf{2}}(\mathbf{M W})$ & Real Part & Imaginary Part \\
\hline 286.67 & 30 & 0 & 8.356094 \\
284.9 & 50 & 0 & 8.325638 \\
282.88 & 70 & 0 & 8.294717 \\
280.65 & 90 & 0.00002 & 8.262435 \\
278.22 & 110 & 0 & 8.228358 \\
275.62 & 130 & 0.00001 & 8.191601 \\
272.84 & 150 & -0.00002 & 8.151964 \\
270.04 & 170 & 0 & 8.106009 \\
267.13 & 190 & -0.00001 & 8.054715 \\
264.05 & 210 & 0 & 7.99837 \\
\hline
\end{tabular}

\section{Conflicts of Interest}

The authors declare no conflict of interest.

\section{References}

1. Baños, R.; Manzano-Agugliaro, F.; Montoya, F.G.; Gil, C.; Alcayde, A.; Gómez, J. Optimization methods applied to renewable and sustainable energy: A review. Renew. Sustain. Energ. Rev. 2011, $15,1753-1766$.

2. Hernández-Escobedo.; Saldaña-Flores, R.; Rodríguez-García, E.R.; Manzano-Agugliaro, F. Wind energy resource in Northern Mexico. Renew. Sustain. Energ. Rev. 2014, 32, 890-914.

3. Aigner, T.; Jaehnert, S.; Doorman, G.L.; Gjengedal, T. The Effect of Large-scale Wind Power on System Balancing in Northern Europe. IEEE Trans. Sustain. Energ. 2012, 3, 751-759. 
4. Joselin, H.G.M.; Iniyan, S.; Sreevalsan, E.; Rajapandian, S. A Review of Wind Energy Technologies. Renew. Sustain. Energ. Rev. 2007, 11, 1117-1145.

5. Montoya, F.G.; Manzano-Agugliaro, F.; López-Márquez, S.; Hernández-Escobedo, Q.; Gil, C. Wind turbine selection for wind farm layout using multi-objective evolutionary algorithms. Exp. Syst. Appl. 2014, 41, 6585-6595.

6. Bu, S.Q.; Du, W.; Wang, H.F.; Chen, Z.; Xiao, L.Y.; Li, H.F. Probabilistic Analysis of Small-Signal Stability of Large-Scale Power Systems as Affected by Penetration of Wind Generation. IEEE Trans. Power Syst. 2012, 27, 762-770.

7. Devbratta, T.; Nadarajah, M. Influence of Constant Speed Wind Turbine Generator on Power System Oscillation. Electr. Power Compon. Syst. 2009, 37, 478-494.

8. Shi, L.B.; Wang, C.; Yao, L.Z.; Wang, L.M.; Ni, Y.X. Analysis of impact of grid-connected wind power on small signal stability. Wind Energ. 2011, 14, 518-537.

9. Bu, S.Q.; Du, W.; Wang, H.F.; Chen, Z.; Xiao, L.Y.; Li, H.F. Probabilistic analysis of small-signal stability of large-scale power systems as affected by penetration of wind generation. IEEE Trans. Power Syst. 2011, 27, 1-9.

10. Soleimanpour, N.; Mohammadi, M. Probabilistic Small Signal Stability Analysis Considering Wind Energy. In Proceedings of the 2nd Iranian Conference on Smart Grids (ICSG), Tehran, Iran, 23-24 May 2012.

11. Slootweg, J.G.; Kling, W.L. The impact of large scale wind power generation on power system oscillations. Electr. Power Syst. Res. 2003, 67, 9-20.

12. Anaya-Lara, O.; Hughes, F.M.; Goran S.J.N. Influence of wind farms on power system dynamic and transient stability. Wind Eng. 2009, 30 107-127.

13. Mendonca, A.; Peas Lopes, J.A. Impact of large scale wind power integration on small signal stability. In Proceedings of the 2005 International Conference on Future Power Systems, Amsterdam, The Netherlands, 16-18 November 2005.

14. Knuppel, T.; Nielsen, J.N.; Jensen, K.H.; Dixon, A.; Ostergaard, J. Small-signal stability of wind power system with full-load converter interfaced wind turbines. IET Renew. Power Gener. 2012, 6 , 79-91.

15. Gautam, D.; Vittal, V.; Harbour, T. Impact of Increased Penetration of DFIG-based Wind Turbine Generators on Transient and Small Signal Stability of Power Systems. IEEE Trans. Power Syst. 2009, 24, 1426-1434.

16. Hagstrom, E.; Norheim, I.; Uhlen, K. Large-scale Wind Power Integration in Norway and Impact on Damping in the Nordic Grid. Wind Energ. 2005, 8, 375-384.

17. Sanchez-Gasea, J.J.; Miller, N.W.; Price, W.W. A Modal Analysis of a Two-Area System with Significant Wind Power Penetration. In Proceedings of the Power Systems Conference and Exposition, New York, NY, USA, 10-13 October 2004.

18. Venkatasubramanian, V.; Jiang, X.; Schattler, H; Zaborszky, J. On the Dynamics of Large Nonlinear Systems with Saturation on Signals and States. In Proceedings of the 34th IEEE Conference on Decision and Control, New Orleans, LA, USA, 13-15 December 1995.

19. Venkatasubramanian, V.; Schattler, H.; Zaborszky, J. Dynamics of Large Constrained Nonlinear Systems-a Taxonomy Theory. Proc. IEEE 1995, 83, 1530-1560. 
20. Kwatny, H.G.; Fischl, R.F.; Nwankpa, C. Local Bifurcation in Power Systems: Theory, Computation and Application. Proc. IEEE 1995, 83, 1453-1483.

21. Kundur, P. Power System Stability and Control; McGraw-Hill: New York, NY, USA, 1994; pp. 700-705.

22. Canizares, C.A.; Mithulananthan, N.; Milano, F. Linear Performance Indices to Predict Oscillatory Stability Problems in Power Systems. IEEE Trans. Power Syst. 2004, 19, 1104-1114.

23. Abed, E.H.; Varaiya, P.P.; Milano, F. Nonlinear Oscillations in Power Systems. Int. J. Electr. Power Energ. Syst. 1984, 6, 37-43.

24. Akhmatov, V. Variable-speed wind turbines with doubly-fed induction generators. Part I: Modelling in dynamic simulation tools. Wind Eng. 2002, 26, 85-108.

25. Yue, H.; Li, G.; Zhou, M. A Probabilistic Approach to Small Signal Stability Analysis of Power Systems with Correlated Wind Sources. J. Electr. Eng. Technol. 2013, 8, 1605-1614.

26. Hansen, A.D.; Jauch, C.; Sørensen, P.; Cutululis, N.; Jauch, C.; Blaabjerg, F. Dynamic Wind Turbine Models in Power System Simulation Tool DIgSILENT; The Risø National Laboratory: Roskilde, Denmark, 2003; pp. 1-82.

27. Fernández, L.M.; Jurado, F.; Saenz, J.R. Aggregated Dynamic Model for Wind Farms with Doubly Fed Induction Generator Wind Turbines. Renew. Energ. 2008, 33, 129-140.

28. Ali, M.; Ilie, I.S.; Milanovic, J.V. Wind farm model aggregation using probabilistic clustering. IEEE Trans. Power Syst. 2008, 28, 309-316.

29. Anderson, P.M.; Fouad, A.A. Power System Control and Stability, 2nd ed.; Wiley: Southern Gate, UK, 2002; pp. 555-582.

30. Guo, X.; Zhao, L.; Tang, Y.; Shen, H. Study on Angle Transient Stability for Wind-thermal-bundled Power Transmitted by AC/DC System. Proc. CSEE 2013, 33, 19-25. (In Chinese)

(C) 2014 by the authors; licensee MDPI, Basel, Switzerland. This article is an open access article distributed under the terms and conditions of the Creative Commons Attribution license (http://creativecommons.org/licenses/by/4.0/). 